Original Article

\title{
PRELIMINARY INVESTIGATIONS INTO THE PHYSICOCHEMICAL AND COMPACTION CHARACTERISTICS OF MODIFIED STARCH OF DISCOREA ALATA USING DICLOFENAC SODIUM TABLET
}

\author{
TIMMA O. UWAH*a, EKAETE I. AKPABI0a, DANIEL E. EKPAa, AKWAOWO E. AKPABIOb, JACOB GODWINa
}

aDepartment of Pharmaceutics, University of Uyo, Nigeria, bDepartment of Clinical and Bio pharmacy University of Uyo, Nigeria Email: tymeuwah@yahoo.com

Received: 18 Nov 2017 Revised and Accepted: 06 Jun 2018

\begin{abstract}
Objective: This work focused on evaluating the micromeritic and compressional properties of pregelatinized African water yam (Discorea alata) starch and its modified forms with comparison to pregelatinized corn starch and microcrystalline cellulose.

Methods: Two modifications of the water yam starch were prepared; acetone dehydrated pregelatinized form (DSA) and an admixture of DSA and pregelatinized corn starch (CDSA). A third form of starch is the acetone dehydrated pregelatinized corn starch (CSA). These were used to form batches compacted as tablets using diclofenac sodium as the active moiety. Physicochemical and flow characteristics of the starch powders were elucidated, and the drug starch compatibility studies done using the Fourier transform Infra-red (FTIR) technique. Compaction studies were investigated on tablets formed at different compression pressures and Heckel plots were prepared.

Results: The slope of the straight line $(\mathrm{K})$ of 0.8959 was greatest for $\mathrm{F}_{1}$ while yield pressure (Py) value of 10.965 was highest for $\mathrm{F}_{3}$. These values from the Heckel plot suggest that while the tablets of control batch of microcrystalline cellulose $\left(\mathrm{F}_{4}\right)$ and a batch of pregelatinized corn starch $\left(\mathrm{F}_{2}\right)$ formed harder compacts, less likely deformed plastically, the Discorea alata batch $\left(\mathrm{F}_{1}\right)$ and the admixed batch $\left(\mathrm{F}_{3}\right)$ were likely to deform plastically. Also, the binding efficiency of the compact was significantly high $\left(47.81 \% \mathrm{Kgscm}^{-1}\right)$ for $\mathrm{F}_{4}$ at $56.5 \mathrm{Kpas}$ compaction pressure, higher than that obtainable for any of the other formulations at the compaction pressures under consideration. All starches formed had similar moisture content (of $10 \%)$ despite the different sources but the interaction between the water molecule and pregelatinized water yam starch improved as revealed by viscosity(7.18mPas), hydration capacity(3.27\%) and swelling index (250\%) of CDSA.
\end{abstract}

Conclusion: It could be concluded that pregelatinized water yam starch could be used as a substitute for corn starch or microcrystalline cellulose as a pharmaceutical excipient (binder/filler) in tablets formulation.

Keywords: Pregelatinization, Compaction, Disccorea alata, Heckel plots

(C) 2018 The Authors. Published by Innovare Academic Sciences Pvt Ltd. This is an open access article under the CC BY license (http://creativecommons.org/licenses/by/4.0/] DOI: http://dx.doi.org/10.22159/ijpps.2018v10i7.23730

\section{INTRODUCTION}

Research questions prompting innovative thinking are constantly on the minds of researchers and manufacturers of excipients. Such questions as; what is likely the next ideal excipient with greater degree of functionality to go for? Will the approval of such adjuvant by the relevant regulatory authorities be a very tall order? How can an existing excipient be improved upon to achieve better dosage forms? No doubt, the search for excipients having improved properties is in no way meagre since the desires and convenience of patients are intended to be achieved in dosage form design, while not compromising therapeutic efficacy.

Starch is widely used as drug excipients, owing to its properties, avalanche and availability. Starches obtained from different sources vary in their respective constitution. Using equations such as Kawakita's and Heckel's and their interpretations, pharmaceutical excipients could be studied and differentiated into plastic or brittle materials. Specifically, the yield pressure in Heckel plot is used as the determining factor [1]. Such knowledge is essential to achieve compacts having the good tensile strength and binding efficiency. Native starch has desirable disintegration properties but its crystalline characteristics give it its poor water solubility [2].

Excipient modification has reportedly knocked off certain undesirable properties inherent in some polymers while introducing newer improved ones [3]. Synthetic, semi-synthetic and natural products have been modified, with derivatives having better flow properties, improved binding properties, emulsification features and even hydrophilic characteristics. Starch, gums, and mucilage have been reportedly modified; chemically by acetylation, carboxymethylation, oxidation; thermally by pregelatinization and even physically by admixture of excipients with different properties $[2,4,5]$.

Diclofenac sodium, a Non-Steroidal Anti-inflammatory Drug (NSAID) is employed clinically for the management of several pain and inflammatory-related conditions such as osteo-and rheumatic arthritis, dysmenorrhoea, and lower back pain.<smiles>O=C(Cc1ccccc1Nc1c(Cl)cccc1Cl)O[Na]</smiles>

Fig. 1: Chemical structure of diclofenac sodium

In recent times many researchers have modified starch with amazing outcomes. One noteworthy advantage reported in their works is the better binding characteristics, reduced crystalinity and improved solubility of the modified starch $[2,3,6]$. Particularly, ethanol and acetone dehydrated pregelatinization have been used to circumvent the main challenge of prolong drying and high energy consumption associated with pregelatinization of starch [5, 7]. A useful question worth asking therefore is do starches of different sources give similar characteristics on pregelatinization? This original work investigates Discorea alata (African water yam) starch, comparing the peculiar 
properties and compaction potentials of the acetone dehydrated pregelatinized forms of the starch (DSA) with that of similarly modified corn starch (CSA), and when the two are admixed (CDSA) using powder of diclofenac sodium as the active pharmaceutical ingredient (API). Microcrystalline cellulose was used as a reference.

\section{MATERIALS AND METHODS}

\section{Materials}

Acetone (BDH Chemicals, UK), cornstarch, water yam starch (obtained from Discorea alata sourced in Uyo metropolis, Nigeria), distilled water, all other chemicals being of analytical grade.

\section{Methods}

\section{Preparation of acetone treated pregelatinized starch}

To a $3.3 \mathrm{~L}$ of distilled water at room temperature, $500 \mathrm{~g}$ of water yam starch was suspended to form a slurry which was then heated to 90 ${ }^{\circ} \mathrm{C}$ forming a mucilage. The mucilage was precipitated with acetone 5 L. The precipitated rubber-like products were cut into small lumps and allowed to cool and dried. The dried products were diminuted using the laboratory blender (Sonic, Japan) and sieved to obtain powder size fraction of $\leq 1.0 \mathrm{~mm}$ which was used for determination of powder characteristics. Cornstarch sample was also subjected to similar treatment to obtain its pregelatinized form.

\section{Physical characterization}

\section{True density}

The true density of powder sample was carried out using the liquid displacement method. Xylene was used as the inert displacement liquid as reported in literature [8]. The numerical value of the parameter was calculated from the equation

$$
D t=\frac{w}{(a+w)-b} \times S G
$$

Where $D_{t}$ is true density, $w$ is the weight of powder sample, SG is the specific gravity of the xylene, a is the weight of the density bottle+xylene, and b is the weight of bottle+solvent+powder sample. This was done in triplicates.

\section{Bulk and tapped density}

A quantity of $10 \mathrm{~g}$ of powder was placed in a 25 ml clean dry measuring cylinder and the volume, $\mathrm{V}_{0}$, occupied by each of the samples without tapping was obtained. After 100 taps at regular intervals, the volume, $V_{100}$ was also determined. The bulk $\left(D_{b}\right)$ and tapped $\left(D_{t p}\right)$ densities were then computed as the ratio of the mass of powder to the volume $\left(\mathrm{V}_{0}\right.$ and $\left.\mathrm{V}_{100}\right)$ respectively.

\section{Carr's index and hausner's ratio}

These were calculated to assess the propensity of the powder samples to be compressed. Carr's index was derived from the formula

$$
\mathrm{CI}=\frac{\mathrm{D}_{\mathrm{tp}}-\mathrm{D}_{\mathrm{b}}}{\mathrm{D}_{\mathrm{tp}}} \times 100
$$

Where CI is the Carr's index as a percentage, $D_{t p}$ is the Tapped density and $D_{b}$ is the Bulk density

For Hausner's ratio, this was calculated as the ratio of the tapped density to the bulk density of the powder samples i.e. tapped density/bulk density

\section{Angle of repose}

The angle of repose was measured using the fixed funnel and freestanding cone method [9]. The tangent of the angle of the powder heap was calculated from the equation

$$
\operatorname{Tan} \propto=\frac{2 \mathrm{~h}}{\mathrm{D}} \ldots \ldots \ldots \ldots(3)
$$

\section{Powder porosity}

Porosity of the powders was derived from the values of bulk and true densities as shown in the equation below;

$$
\mathrm{e}=1-\frac{\mathrm{D}_{\mathrm{b}}}{\mathrm{D}_{\mathrm{t}}} \times 100
$$

Where $D_{b}$ and $D_{t}$ are the bulk and true densities respectively

\section{Moisture sorption profiles}

Specifically $2 \mathrm{~g}$ of the powder sample was accurately weighed and evenly distributed over the surface of a $70 \mathrm{~mm}$ petri dish. The samples were then placed in a large desiccator containing distilled water in its reservoir (100\%) at room temperature and the weight gained by the exposed samples over a seven-day period was recorded and amount of water absorbed calculated from the weight difference [10].

\section{Loss on drying}

A $5 \mathrm{~g}$ quantity of the powder sample was transferred each to a petri dish and then dried in an oven at $105^{\circ} \mathrm{C}$ until a constant weight was obtained. The percentage (\%) moisture content was then determined as the ratio of weight of moisture loss to weight of sample expressed as percentage [11]

$$
\mathrm{LOD}=\frac{\mathrm{Wi}-\mathrm{Wf}}{\mathrm{Wi}} \times 100
$$

Where LOD =Loss on drying, $\boldsymbol{W} \boldsymbol{i}$ is the initial weight of the sample and $\mathrm{Wf}$ is the final weight

\section{Swelling index}

The swelling index of the powder was carried out is described as follows: A quantity (1g) of the powder sample was placed in $15 \mathrm{ml}$ calibrated centrifuge tubes and the volume occupied was noted as $\mathrm{V}_{1}$. Specifically $10 \mathrm{ml}$ of distilled water was added and stoppered. The contents were mixed on a vortex mixer (XH-Stuart, UK) for 2 min. The mixture was allowed to stand for $10 \mathrm{~min}$ and centrifuged immediately at 1000 revolutions per minute (rpm) for $10 \mathrm{~min}$ on a bench top centrifuge (Model 80-2). The supernatant was carefully decanted and the volume of sediment recorded as $V_{2}$ [10]. The swelling index was computed using equation 6 below;

$$
\mathrm{S}=\frac{\mathrm{V}_{2}-\mathrm{V}_{1}}{\mathrm{~V}_{1}} \times 100
$$

Where $\mathrm{S}$ is the swelling capacity, $\mathrm{V}_{2}$ is the volume of the hydrated powder, and ${ }_{1}{ }_{1}$ is the volume of powder before hydration.

\section{Hydration capacity}

The method for determination of the hydration capacity was patterned after that used by Kornblum and Stoopak and described by Owhoavworhua [5]. It was carried out during the same time the swelling capacity was done but instead of the volume of sediment, the weight was determined. The hydration capacity was calculated as the ratio of the weight of sediment to the dry sample weight as shown in the equation below:

$$
\mathrm{HC}=\frac{\mathrm{W}_{2}-\mathrm{W}_{1}}{\mathrm{~W}_{1}} \times 100 \ldots \ldots(7)
$$

Where $\mathrm{HC}$ is the Hydration capacity, $\mathrm{W}_{2}$ the sediment weight and $\mathrm{W}_{1}$, the sample weight

\section{Fourier-transform infrared spectra}

The surface of the starch (Discorea alata) sample was characterized using Perkin Elmer spectrum 100 Fourier transform Infrared spectrophotometer. Each starch sample was scanned at a wavelength of between $4000 \mathrm{~cm}^{-1}$ and $400 \mathrm{~cm}^{-1}$. The diclofenac sodium powder was equally scanned using the same device. An admixture of the each starch sample with diclofenac sodium powder was prepared and equally scanned respectively.

\section{Compaction properties}

\section{Preparation and analysis of tablets}

Tablets weighing $400 \mathrm{mg}$ each made up of diclofenac sodium and pregelatinized water yam starch was produced using a single punch Carver Hydraulic press (Model C, USA) at compression pressures from 0.25 to 1.25 tonnes corresponding to the compression pressures $27.3 \mathrm{KPa}-163.5 \mathrm{KPa}$ respectively. Fifteen tablets were compacted at each pressure and retention time being 30s. Prior to compression, the die and the flat-faced punches were lubricated with $1 \%$ magnesium stearate in acetone. The tablets were stored in air-tight container for 
$24 \mathrm{~h}$ (to allow for elastic recovery) before evaluation. Parameters of the tablets such as thickness ( $t$ ), diameter (D), and weight uniformity of the tablets were determined. Also, the crushing strength (Cs) was ascertained using the Monsanto hardness tester (MHT-20, UK). The relative density $\mathrm{D}$ was calculated as the ratio of the density of the tablet to the true density of the starch samples, from which Heckel plots were carried out over a compression range of $136.2 \mathrm{KPa}$ and the parameters from Heckel plots deduced. The density of the tablet is a ratio of the weight of tablet to its volume. The area under the Heckel curve (AUHC) was calculated by the Trapezoidal method and used to express the extent of volume reduction that the material had undergone during the entire compression pressure range.

$$
\mathrm{D}=\frac{\mathrm{Wt}}{\mathrm{VtDt}} \cdot .(7)
$$

Where Vt is the volume of the tablet in $\mathrm{ml}$, and Dt is the true density, $\mathrm{g} / \mathrm{ml}$, of the starch powder.

The compaction potential of the powders was studied using the Heckel equation

$$
\ln \left(\frac{1}{1-D}\right)=K \cdot P+A
$$

$\mathrm{D}$ is the relative density of the compact with reference to the material being compacted, $\mathrm{P}$ is the applied pressure, and $\mathrm{K}$ (the slope of the straight line portion) is the reciprocal of the yield pressure, Py, of the starch material. The yield pressure is inversely related to the ability of the material to deform plastically under pressure and $\mathrm{A}$ is a function of the original tablet volume. It is a constant representing particle rearrangement [1]. The relative density $\mathrm{D}$ was obtained from a ratio of the density of compact to the true density also derivable from

$$
\mathrm{D}_{1}=1-\mathrm{e}^{-\mathrm{A}}
$$

The relative density becomes $\mathrm{D}_{0}$ when the applied pressure is equal to zero $\left(\mathrm{D}_{0}=\right.$ loose density/true density), is used for the description of initial particle rearrangement and densification due to die filling. A high value would indicate very dense packing.
The tensile strength (Ts) was calculated from:

$$
\mathrm{Ts}=\frac{2 \mathrm{Cs}}{\mathrm{nDt}}
$$

Where 1 metric ton $=9.8 \mathrm{~N}$. The degree of compatibility of the material (that is the strength of the material) was deduced from the plot of the tensile strength, against the respective compression pressures.

\section{Hardness, friability and disintegration time}

The crushing strength (hardness) of the compacts was carried by diametrical compression using Monsanto hardness tester (MHT-20, UK). Each tablet was placed between the plates of the tester and the knobs screwed until enough pressure caused breakage and the force noted.

The Veego Friability apparatus (BT-2D) was used for determining friability, wherein 5 tablets were pre-weighed and placed in the friabilator allowed to operate at 25 revolutions per minute for $4 \mathrm{~min}$. After the test, tablets were recovered, dusted re-weighed. The percentage friability was calculated as;

$$
\text { Friability }=\frac{\text { loss in weight }}{\text { initial weight }} \times 100 \text {. }
$$

The time it takes the tablet to disintegrate into particles that can diffuse through the mesh was determined in $0.1 \mathrm{NHCl}$ using the $\mathrm{BP}$ disintegration apparatus.

The values of the parameters were used to calculate the binding efficiency.

\section{Binding efficiency}

To ascertain the potency of the pregelatinized starch as a binder, the binding capacity of the tablets was calculated for from the following equation.

$$
\text { Binding efficiency }=\frac{\text { Hardness }}{\text { Friability }} \times \frac{1}{\text { disintegration time }}
$$

\section{RESULTS}

Table 1: Micromeritic properties of the starch powders

\begin{tabular}{lllllll}
\hline $\begin{array}{l}\text { Starch } \\
\text { powders }\end{array}$ & $\begin{array}{l}\text { Bulk } \\
\text { density } \\
(\mathbf{g} / \mathbf{m l})\end{array}$ & $\begin{array}{l}\text { Tapped } \\
\text { density } \\
(\mathbf{g} / \mathbf{m l})\end{array}$ & $\begin{array}{l}\text { True density } \\
\mathbf{( g / m l )}\end{array}$ & $\begin{array}{l}\text { Angle of } \\
\left.\text { repose( }{ }^{\circ}\right)\end{array}$ & $\begin{array}{l}\text { Hausner's } \\
\text { ratio }\end{array}$ & $\begin{array}{l}\text { Compressibility } \\
\text { Index } \\
(\%)\end{array}$ \\
\hline CSA & $0.42 \pm 0.01$ & $0.67 \pm 0.05$ & $1.67 \pm 0.09$ & $25.28 \pm 0.10$ & $1.59 \pm 0.1$ & $37.12 \pm 3.12$ \\
DSA & $0.41 \pm 0.02$ & $0.56 \pm 0.01$ & $1.64 \pm 0.13$ & $36.25 \pm 0.41$ & $1.36 \pm 0.04$ & $26.74 \pm 4.72$ \\
CDSA & $0.44 \pm 0.03$ & $0.63 \pm 0.12$ & $1.65 \pm 0.22$ & $12.53 \pm 0.35$ & $1.45 \pm 0.05$ & $30.90 \pm 2.13$ \\
\hline
\end{tabular}

Key: CSA, Pregelatinized Corn Starch; DSA, Pregelatinized Water yam starch; CDSA, a mixture of pregelatinized corn starch and water yam starch. Values are presented as mean \pm standard deviation (SD). Where the number of the experiment (n) is $=3$

Table 2: Physicochemical properties of the starch

\begin{tabular}{llllll}
\hline $\begin{array}{l}\text { Starch } \\
\text { powders }\end{array}$ & pH & $\begin{array}{l}\text { Moisture } \\
\text { Content (\%) }\end{array}$ & $\begin{array}{l}\text { Viscosity } \\
\text { (mPas) }\end{array}$ & $\begin{array}{l}\text { Hydration } \\
\text { capacity (\%) }\end{array}$ & $\begin{array}{l}\text { Swelling } \\
\text { capacity (\%) }\end{array}$ \\
\hline CSA & $6.28 \pm 0.07$ & $10 \pm 1.73$ & $8.56 \pm 0.52$ & $3.47 \pm 0.14$ & $330 \pm 14$ \\
DSA & $5.64 \pm 0.38$ & $10 \pm 1.00$ & $6.28 \pm 0.22$ & $3.04 \pm 0.15$ & $2.0 \pm 0.00$ \\
CDSA & $6.13 \pm 0.69$ & $10 \pm 1.73$ & $7.18 \pm 0.45$ & $3.27 \pm 0.23$ & $2.0 \pm 0.01$ \\
\hline
\end{tabular}

Key: values are presented as mean \pm standard deviation and number of the experiment (n) is 3

Table 3: Composition of the diclofenac compact

\begin{tabular}{lllll}
\hline Ingredients* & F1 & F2 & F3 & F4(control) \\
\hline Diclofenac & 200 & 200 & 200 & 200 \\
DSA & 136 & - & - & - \\
CSA & - & 136 & 136 & - \\
CDSA & - & - & 64 & - \\
MCC & 64 & 64 & 400 & 200 \\
Total weight(mg) & 400 & 400 & 400 \\
\hline
\end{tabular}

*Lubricant used was magnesium stearate in $1 \%$ acetone during compression. 


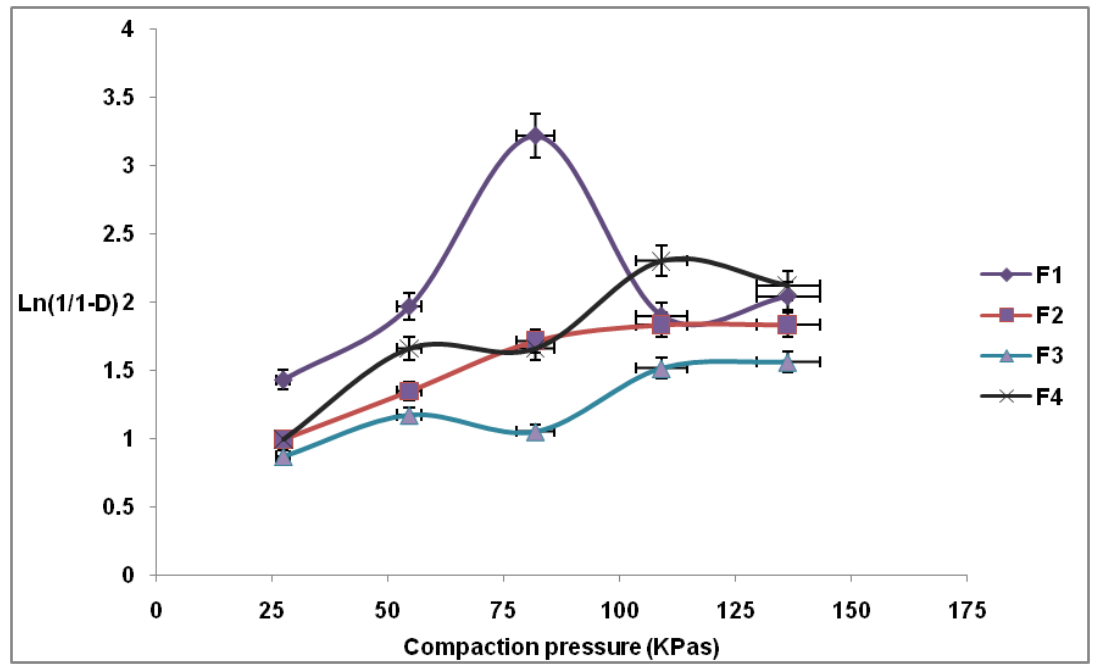

Fig. 2: Heckel plots of compacts of the different powder samples

Table 4: Values from heckel plot

\begin{tabular}{lllll}
\hline Batch code & $\mathbf{R}^{\mathbf{2}}$ & AUHC(Kpas) & K & A \\
\hline F1 & 0.9498 & 238.025 & 0.8959 & 0.4123 \\
F2 & 0.999 & 166.775 & 0.3603 & 0.6315 \\
F3 & 0.3557 & 129.55 & 0.0912 & 0.8472 \\
F4 & 0.75 & 188.75 & 0.3332 & 0.7421 \\
\hline
\end{tabular}

Key: linearity of the curve was taken at 3 points between 25 and $80 \mathrm{KPas}$ of the compaction pressure

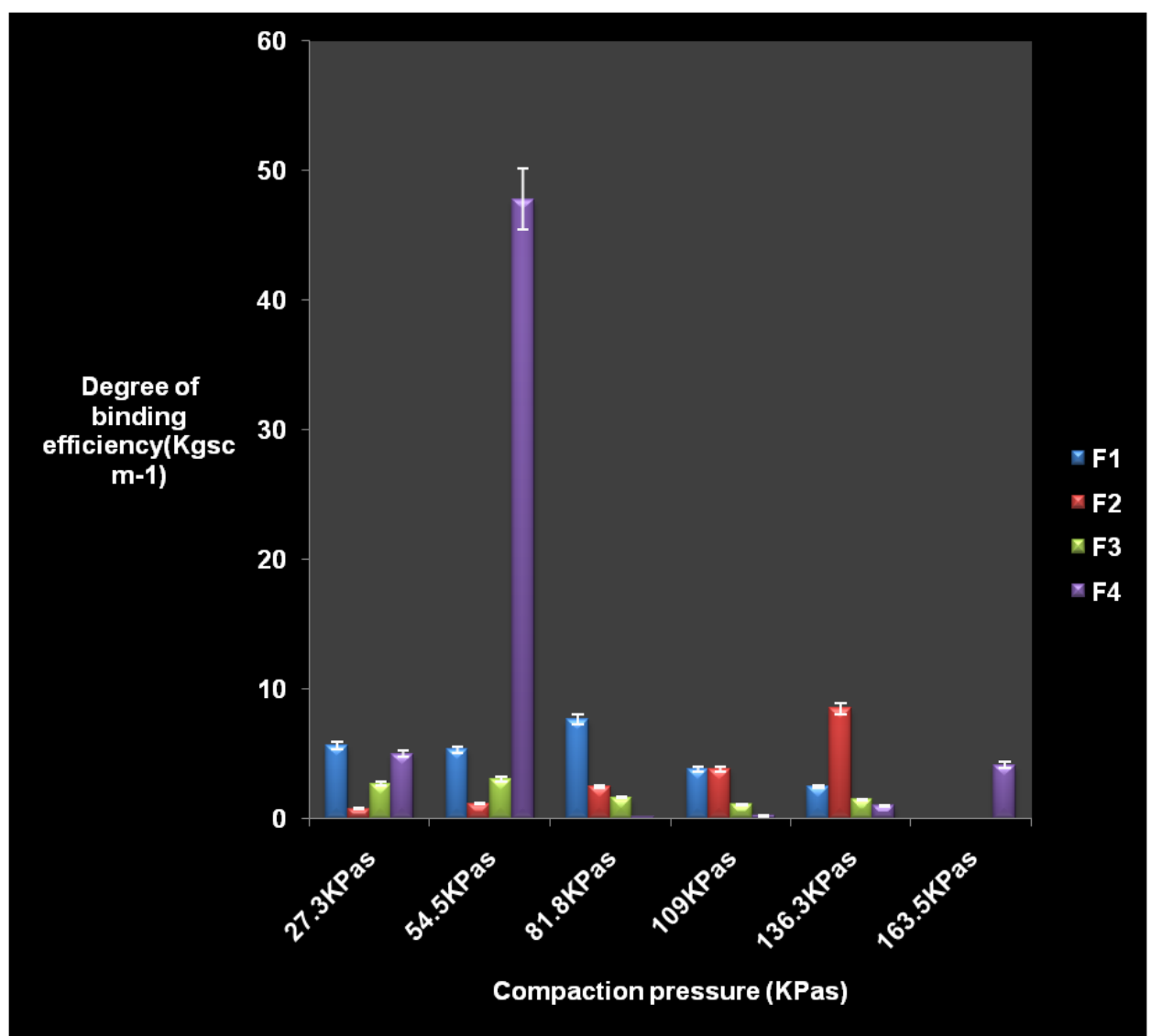

Fig. 3: Plot showing binding efficiency of compacts at different compaction pressures, three tablets were randomly selected and used for the determination for each batch at the respective pressure 


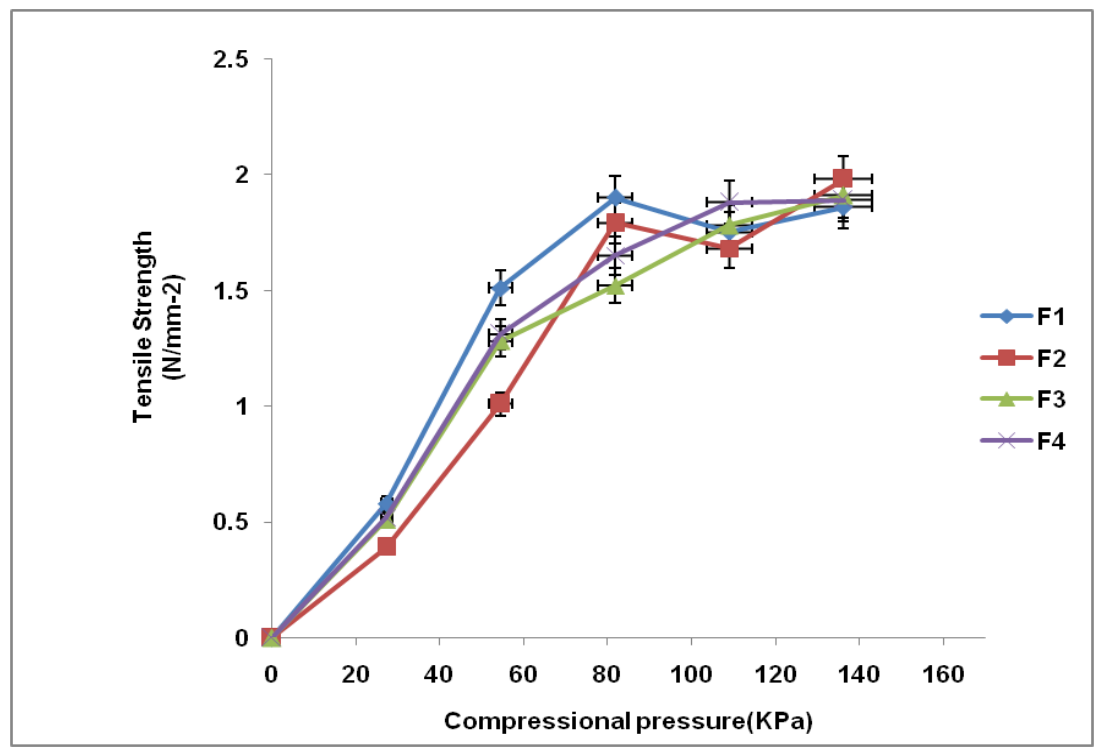

Fig. 4: Tensile strength-compressional pressure relationship, 3 tablets were used for the determination at the respective pressures

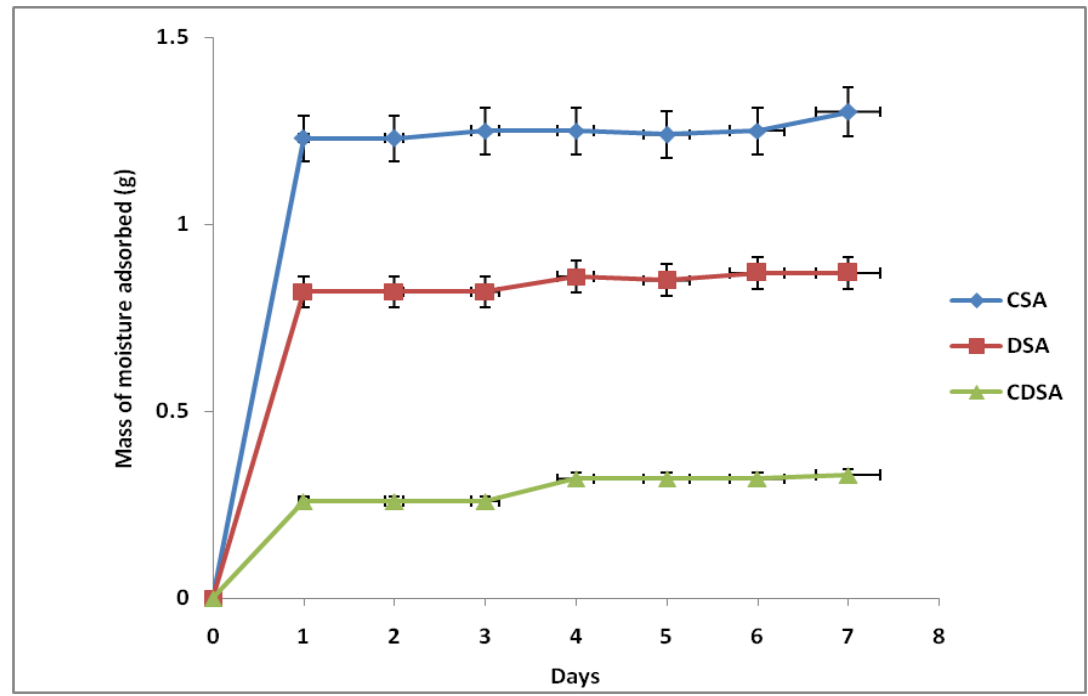

Fig. 5: Sorption profile of pregelatinized Starches, a sample size of $2 \mathrm{~g}$ each was used and experiment done in triplicate for each sample

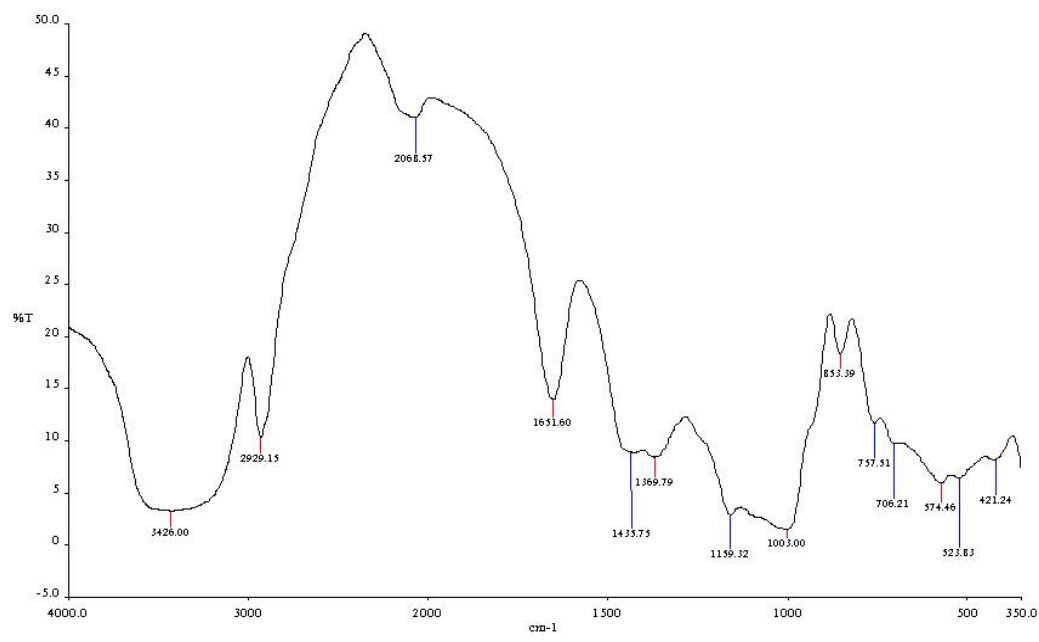

Fig. 6: FTIR for pregelatinized Discorea alata (DSA) 


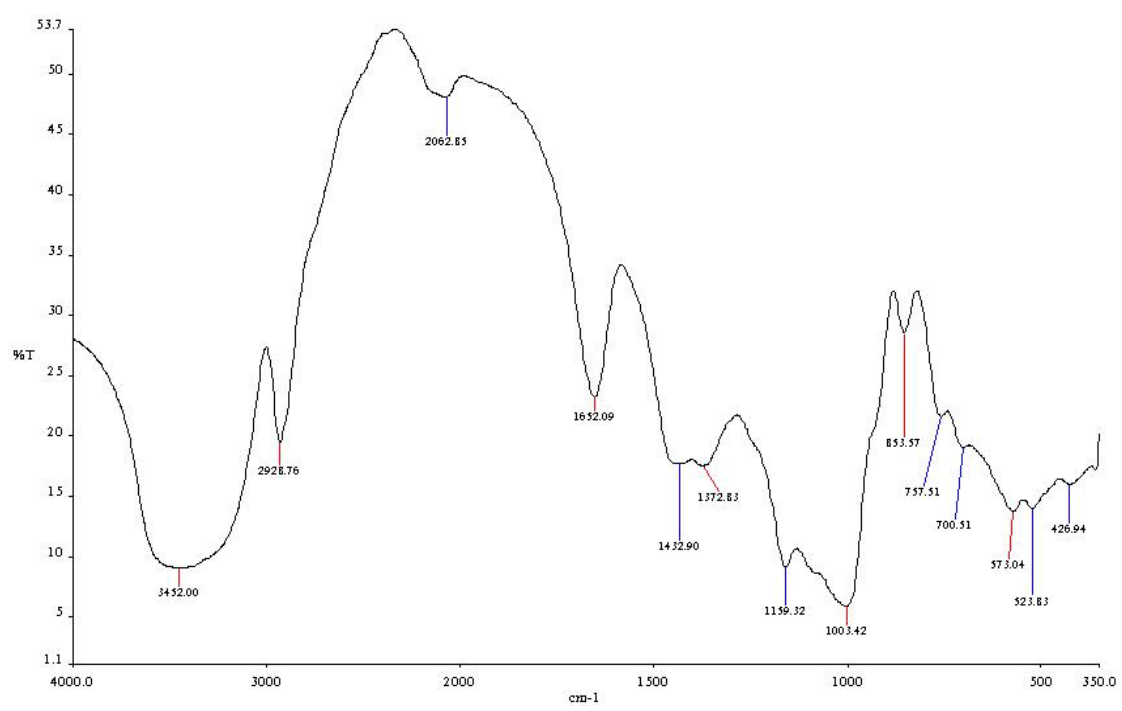

Fig. 7: FTIR for pregelatinized corn starch (CSA)

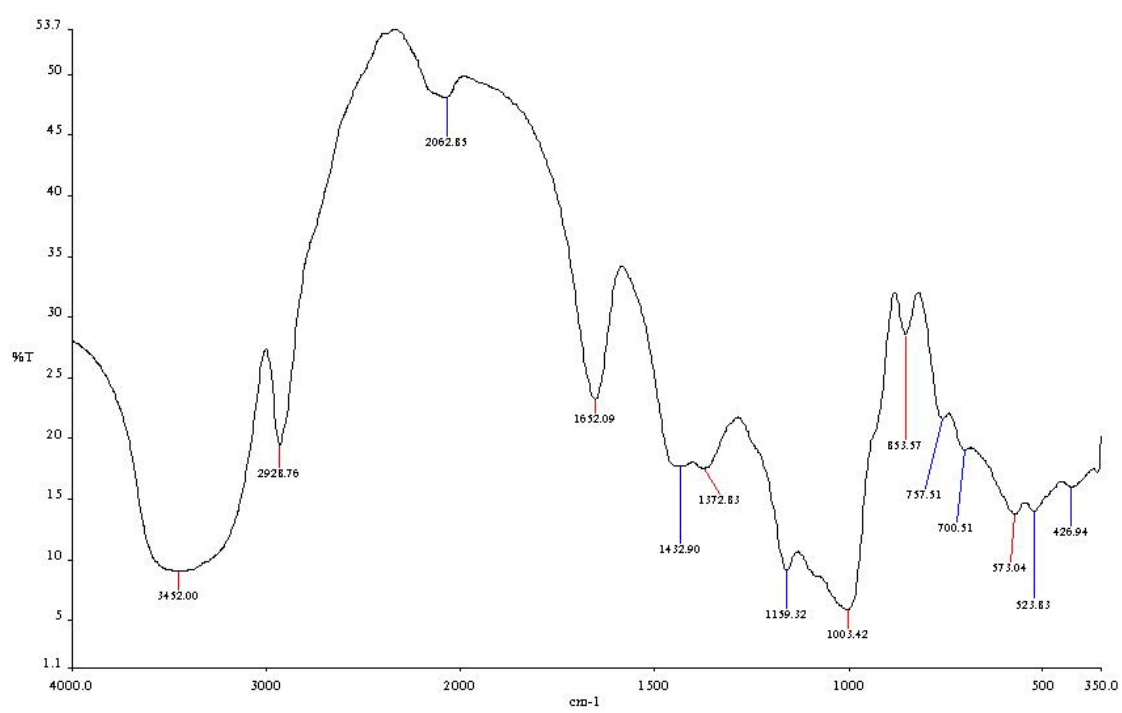

Fig. 8: FTIR for admixed pregelatinized starches (CDSA)

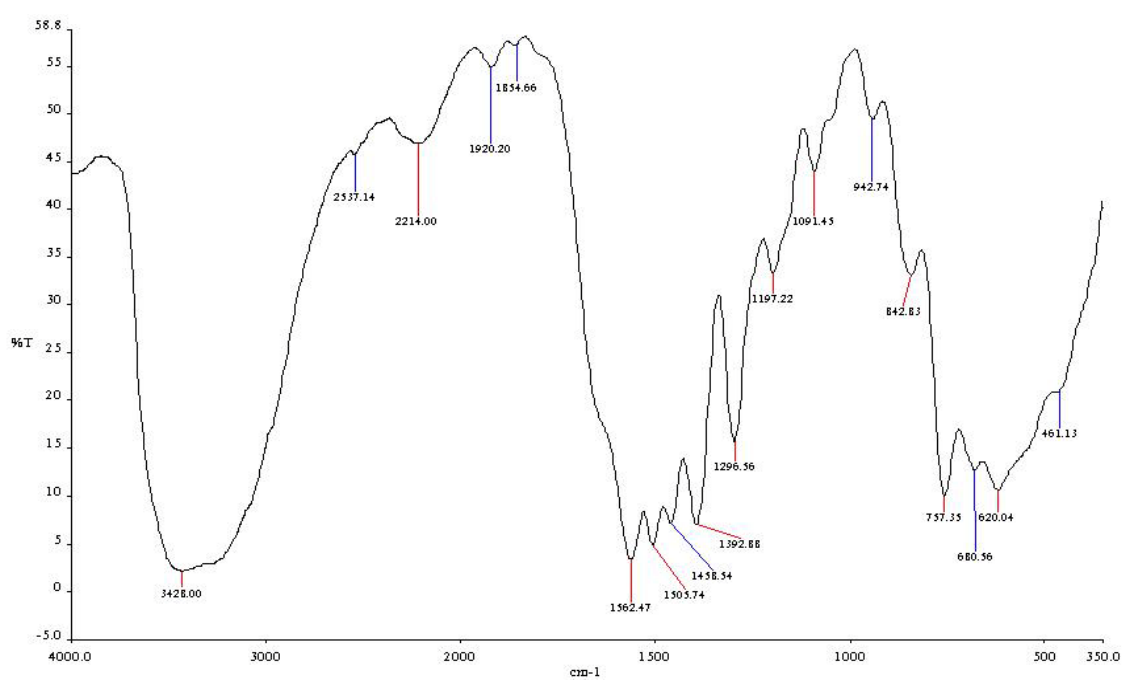

Fig. 9: FTIR for pure Diclofenac sodium 


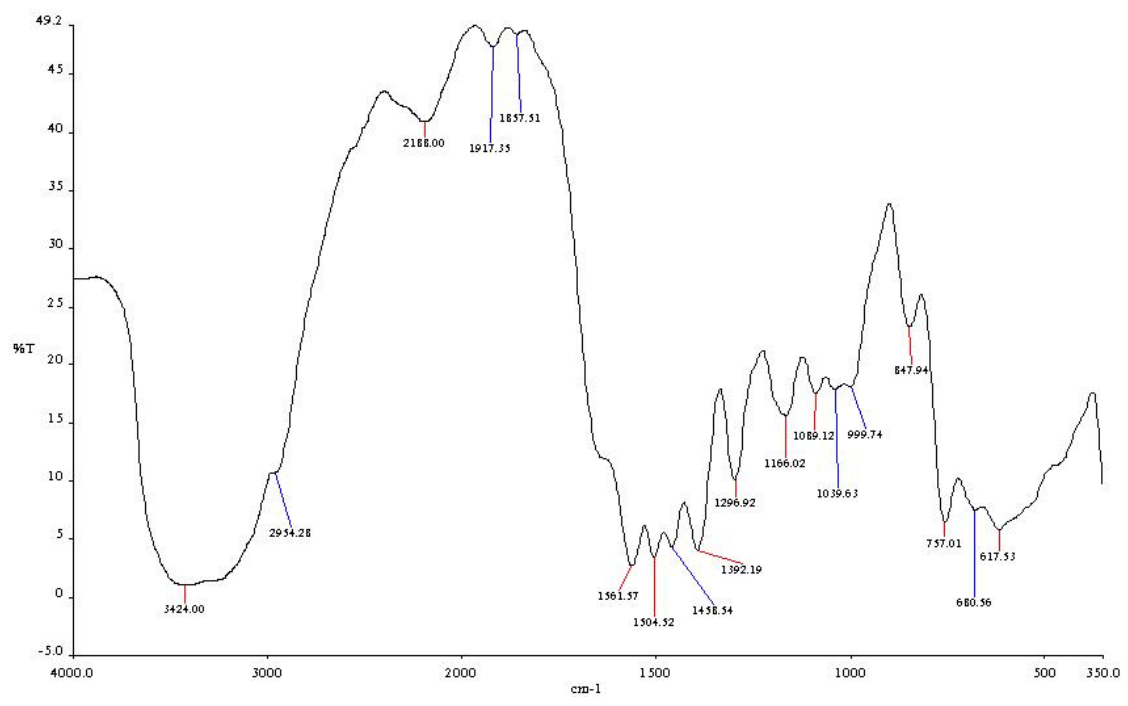

Fig. 10: FTIR for Discorea pregelatinized Discorea alata+Diclofenac

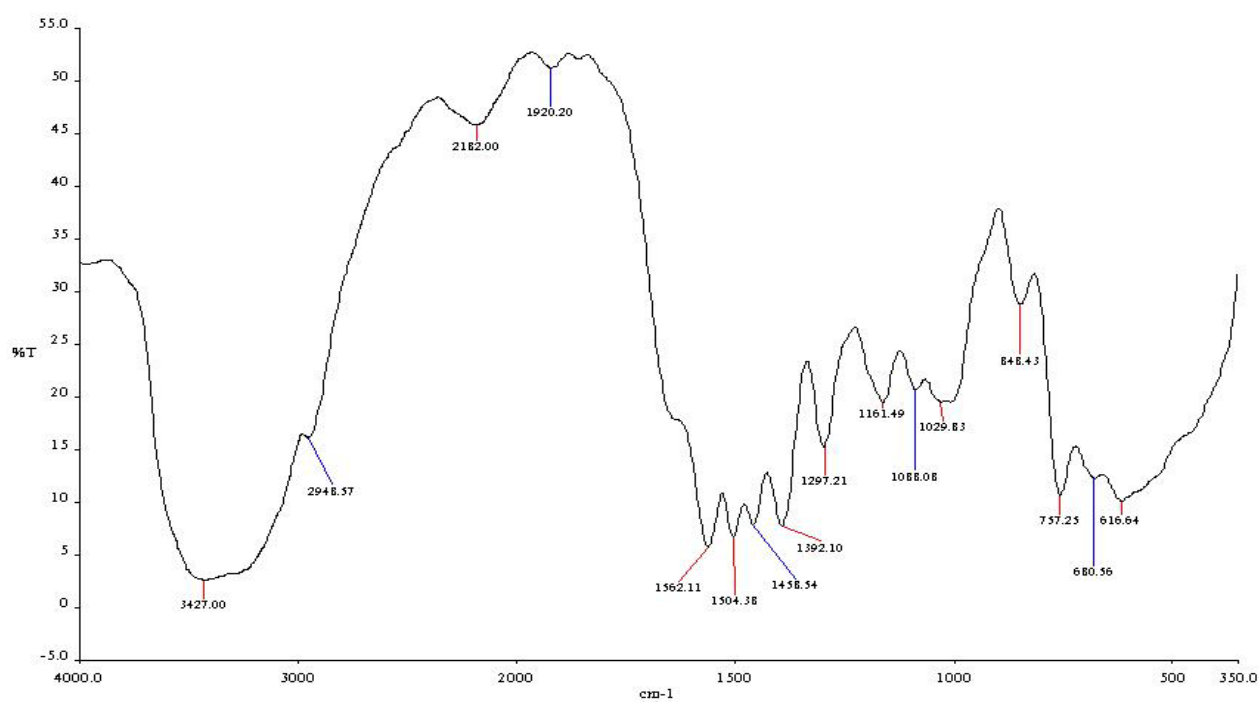

Fig. 11: FTIR for pregelatinized corn starch (CSA)+diclofenac

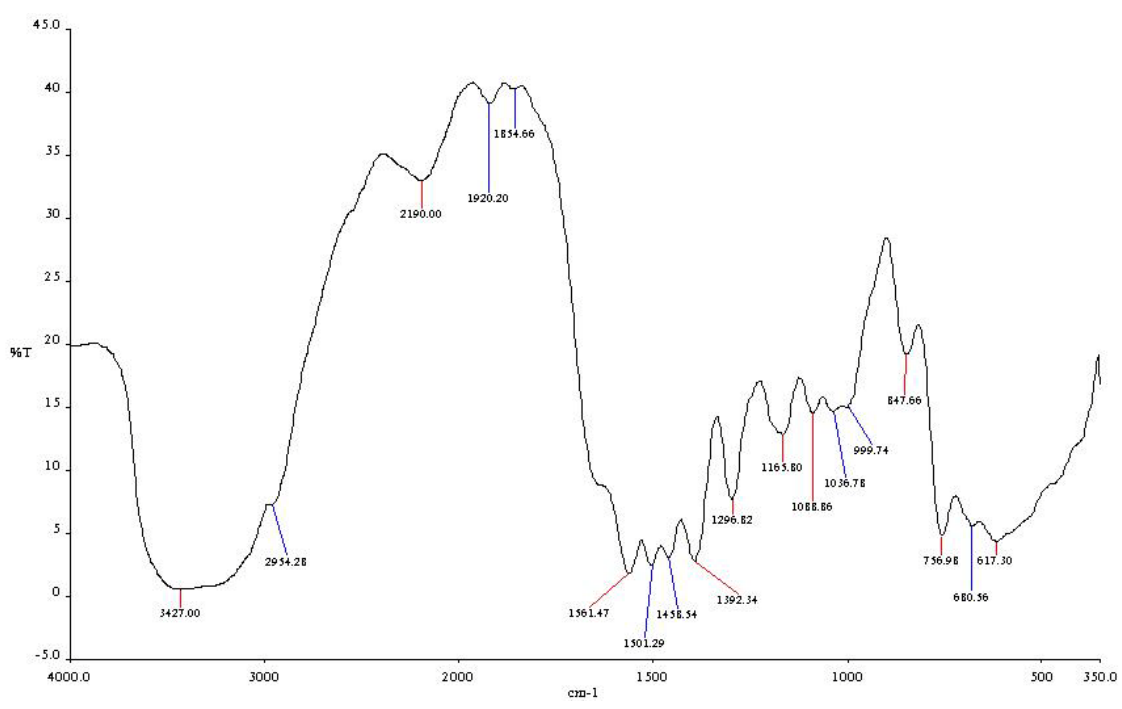

Fig. 12: FTIR for admixed pregelatinized starches (CDSA) and diclofenac 
Table 5: Main peaks observable in the FTIR spectra of the modified starches and diclofenac

\begin{tabular}{lll}
\hline S. No. & Wave numbers $\left(\mathbf{c m}^{-1}\right)$ & Possible functional groups present \\
\hline 1 & $3426-3457$ broad smooth & $-\mathrm{OH}$ of the starches \\
2 & 2928 Sharp peaks & $\mathrm{CH}-\mathrm{CH} 2$ \\
3 & 1692 & $\mathrm{C}=\mathrm{O}$ stretch of an aldehyde group in the starches \\
4 & 3452 peak & $-\mathrm{OH}$ of Carboxylic group \\
5 & 757,680 peaks & $-\mathrm{Cl}$ atoms of diclofenac \\
6 & 1562,1505 & $\mathrm{C}=\mathrm{C}$ stretch in aniline of diclofenac \\
\hline
\end{tabular}

\section{DISCUSSION}

The ease and proper filling of the die cavity of the tabletting machine during direct compression is related to the flow property of the powdered material [12]. Powders with Hausner's ratio (HR) of value $<1.2$ show good flow. Those with values in the range 1.25-1.5 require the use of glidants to improve the flow while those with values $>1.5$ as seen in powders with flakes indicate poor flow. Values of Carr's index of range 1-10\% indicate powders with the excellent flow; $11-15 \%$ describes a good flow and higher values such as 16$20 \%$ means flow that is fair while powders with extremely poor flow have greater than $40 \%$ Carr's index [9]. The indirect indicators of flowability (angle of repose, Carr's index and Hausner's ratio) from table 2 show the powders have poor flow with the pregelatinized corn starch exhibiting lowest values. Hausner's ratios for all the powders were greater than 1.25 and the values for Carr's index are higher than $20 \%$, these reflect poor flowability. The order is as follows DSA>CDSA>CSA. Admixed powder (CDSA) showed only slightly improved flow over the pregelatinized corn starch (CSA). One possible reason for this observation could be that the particles of the DSA are well interspersed between those of the CSA thus enhancing the flow property slightly.

The FTIR was employed for determining the compatibility of the pregelatinized starches with the diclofenac sodium powder as well as the functional groups present in the pregelatinized starches. The broad smooth intense peak found at $3426 \mathrm{~cm}^{-1}$ (for water yam) and $3452 \mathrm{~cm}^{-1}$ (for corn starch) are attributable to the diagnostic-OH groups whereas the sharp peaks attached laterally to the $\mathrm{OH}$ peaks found at $2928 \mathrm{~cm}^{-1}$ for both spectra characteristic for water yam and cornstarch represents the $\mathrm{CH}_{2}-\mathrm{CH}_{2}$ chains of the starch $[13,14]$. Peak seen at $1692 \mathrm{~cm}^{-1}$ on all the pregelatinized starch spectra is attributable to $\mathrm{C}=\mathrm{O}$ stretch of an aldehyde. It is no surprise as starches are aldehyde compounds. The functional groups present in the pregelatinized starch are similar to that in the native starch as reported in literature 5 . It could be inferred then that pregelatinization did not introduce any new functional group nor knock off any pre-existing one, hence it is not a chemical modification method but only affected the rearrangement of the powder particle. The key peaks of the pure diclofenac reveal the presence of- $\mathrm{OH}$ group of the carboxylic functional group (3452 $\mathrm{cm}^{-1}$ peak), the-Cl groups $\left(757 \mathrm{~cm}^{-1}, 680 \mathrm{~cm}^{-1}\right)$ and the aromatic $\mathrm{C}=\mathrm{C}$ stretch in the aniline rings $\left(1562 \mathrm{~cm}^{-1}, 1505 \mathrm{~cm}^{-1}\right)$ present [14]. The admixed diclofenac sodium powder with the respective starches did not shift or cancel out the prominent diagnostic peaks of the starches or that of the diclofenac. This implies that the pregelatinized starch was compatible with the diclofenac.

The Heckel plot (fig. 2) graphically represents how the powders behave in the presence of compressional force applied to form compact. It is developed on the assumption that powder compression follows a first order of reaction with the powder voids acting as 'reactants' and the compacts(having reduced porosity) being the products [15]. Values obtained at appropriate points on the plots classify the sample powders based on their behaviour under pressure. For example, larger $\mathrm{K}$ values (slope of the linear part of the plot) indicate harder compacts [5]. K also relates the minimum pressure necessary to cause a permanent deformation in the sample powder [17]. From table $4, F_{2}$ and $F_{4}$ values are similar; while $F_{1}$ is highest, $F_{3}$ is lowest. This implies that $F_{2}$ and $F_{4}$ (composing of DSA and MCC respectively) would form compacts that are harder than those of $F_{3}$. The $F_{1}$, however, will form the hardest compacts of the four samples. This explains the tensile strength-compression force plot (fig. 4) which reflects such higher value in hardness as force of compression increased. This obvious trend is further corroborated (in fig. 3) where the binding efficiency has a steady rise with increasing compression pressure for $F_{2}$. The binding efficiency of $F_{1}$ on the other hand was consistently higher than others. One reason could be that higher compressional force favoured close-knit consolidation of the molecules of $F_{2}$ and $F_{1}$ possibly by fusion bonding.

The mean yield pressure (Py) in the Heckel equation is a descriptive term inversely related to the ease of plastic deformation of a powdered material to form a compact under pressure. A lower value will indicate a faster onset and degree of plastic deformation and vice-versa [18]. It is derived from the inverse of $\mathrm{K}$ value and has to be obtained from the linear portion of the curve since the Heckel plots are not completely linear. It is worthy of note that the deviation from linearity of Heckel plot, at low compaction pressure, is due to particle reorganization/repositioning but, at higher pressure, the linearity drift is because of elastic deformation of compact (9). Yield pressure is dependent on the material and as such can be used to classify pharmaceutical materials. Thus the higher the Py value, the lesser the tendency for plastic deformation to occur under pressure and vice-versa $[18,9]$. Table 3 reveals that the Py is highest for $F_{3}$ formulation and follows the order $F_{3}>F_{4}>F_{2}>F_{1}$. Thus pregelatinized water yam starch will more readily deform plastically than pregelatinized corn starch, but the ease of the former to undergo plastic deformation under pressure is significantly reduced on admixture with the latter. However the Py value is influenced by $\mathrm{R}^{2}$ values which is also a significant predictor of extent of compressibility via plastic deformation. The closer the $\mathrm{R}^{2}$ is to unity, the likely for plastic deformation but the lesser, the likely conclusion for fragmentation propensity [17] and with $F_{3}$ so distant from unity it goes to suggest that its mechanism for deformation is possibly due to particle fragmentation. The AUHC obtained from Heckel plot is a useful estimate of compressibility. The greater the AUHC value the more compatible the powder [17]. From table $4, \mathrm{~F}_{1}$ has the highest value of $A U H C$ and the order is $F_{1}>F_{4}>F_{2}>F_{3}$.

As shown in fig. 4, the increase in compression pressure, the greater the tensile strength for all the four compacts. $\mathrm{F}_{1}$ measured similarly as $F_{2}$ and $F_{4}$ at the same compression pressure. From compressional force of $0-100 \mathrm{KPas}, \mathrm{F}_{1}$ showed the highest tensile strength but $\mathrm{F}_{2}$ was lowest. Above the $100 \mathrm{KPas}$ where the $\mathrm{F}_{1}$ became the lowest and tensile strength for $F_{2}$ became highest at increased compression pressure. How compacted a tablet is has been linked to the amount of loading pressure which brings about close proximity of the particles being tableted so that they are held together by cold welding or fusion bonding [20]. Generally higher tensile strength reflects strong interparticulate bond formation, harder compacts and is proportional to the compression force [9]. Thus to form harder tablets of $F_{2}$, compression pressure will be optimized at above 100KPas.

Although having the same moisture content and loss on drying, the different pre-gelatinized starches possess separate interactions with water molecules as revealed by the viscosity, hydration capacity and the swelling index. Similar moisture content implies that the class of drugs that pregelatinized corn starch (CSA) has been used for as a pharmaceutical aid can also be used with pregelatinized water yam starch (DSA) with no fears of consequent incompatibility occurring from drug-excipient interaction possibly due to hydrolysis. CSA has the highest interaction with water whereas DSA possess the lowest. As expected, an admixture of the two gave an intermediary value. High moisture content is no far distant from that reported in literature that pregelatinized starch undergoes 'starch granule de- 
structuralisation' which in turn allows for good water penetration and retention [5]. That a tablet will readily disintegrate could be seen in its index of swelling. The physicochemical properties of hydration capacity and swelling capacity are inter-related and are good indicators reflecting the swelling of the tablets and thus its subsequent ease of disintegration [21]. Each of those indicators describes the different relationships of water molecules with the pharmaceutical aid. For example the swelling index reflects the increase in volume of sample, after water absorption, while the hydration capacity is the amount of water molecule that can be absorbed and held in the excipient after exposure to water. Table 3 shows that for the powders, the swelling index and the hydration capacities follow the same trend, CSA having the highest value while CDSA had improved properties. Such modification mainly could be due to 'proximal intermolecular association' of particles of the different powders. It goes with reason that such association 'opens up' the molecules of DSA for improved water penetration; a good property looked for in disintegrants.

However, it is noteworthy that although all powders had a same moisture content, moisture sorption profile reveals that the CSA possessed higher sensitivity to atmospheric moisture over the DSA and its admixture (fig. 5). Unlike the relative improvement of the admixed powders in other moisture-related indicators, (swelling index and hydration capacities), the 'proximal interparticle association' reduced the effective surface area of the CSA thereby reducing its effective attraction of water moisture. Higher moisture content in a pharmaceutical powder can influence its flow properties, containers for storage and affect negatively any incorporated drug that can hydrolyse in the presence of moisture.

\section{CONCLUSION}

Pregelatinized water yam starch would be a good pharmaceutical excipient as a binder/filler for immediate release or delayed tablet just like the standard is known as cornstarch and microcrystalline cellulose. However physical admixture of the two improved the physicochemical and compaction properties of the former and would provide an alternative to employing only corn starch as an adjuvant to tablet manufacture.

\section{CONFLICT OF INTERESTS}

We declare no conflict of interests

\section{AUTHORS CONTRIBUTIONS}

Timma $\mathrm{O}$ and Jacob G designed the work, collected assemebled the data. Daniel E wrote the manuscript and analysed the data. All the authors critically revised and approved the final manuscript.

\section{REFERENCES}

1. Hooper D, Clarke FC, Mitchell JC, Snowden MJ. A modern approach to heckel equation: the effect of compaction pressure on the yield pressure of ibuprofen and its sodium salt. J Nanomed Nanotech 2016;7:1-6.

2. Michaud J. Starch-based excipients for pharmaceutical tablets in pharmaceuticals. Pharma Chem; 2002. p. 42-4.

3. Majzoobi M, Radi M, Farahnaky A, Jamalian J, Tongdang T, Mesbahi Gh. Physicochemical properties of pre-gelatinized wheat starch produced by a twin drum drier. J Agric Sci-Tech 2011;13:193-202.
4. Adeyanju O, Lajide L, Edah AO, Adesemuyi MF, Plavec J. Effect of acetylation on the physicochemical characteristics of Sweitenia mycrophylla gum, a potential excipient. J Pharm Appl Chem 2016;2:24-30.

5. Ohwoavworhua FO, Osinowo A. Preformulation studies and compaction properties of a new starch-based pharmaceutical aid. Res J Pharm Bio Chem Sci 2010;1:255-70.

6. Priyanka N, Chauhan I, Yasir M. Insights into polymers: film formers in mouth dissolving films. Drug Invent Today 2011;3:280-9.

7. Khalid GM, Musa H, Olowosulu AK. Evaluation of filler/binder properties of modified starches derived from Plectranthus esculentus by direct compression in metronidazole tablets formulations. Pharm Anal Acta 2016;7:1.

8. Chukwuemeka C Mbah, Philip F Builders, Godwin C Akuodor, Olobayo 0 Kunle. Pharmaceutical characterization of aqueous stem bark extract of Bridelia ferruginea benth. Trop J Pharm Res 2012;11:637-44.

9. Aulton ME, Taylor, KMG Aulton's. Pharmaceutics the design and manufacture of medicine. $4^{\text {th }}$ ed. London: Elsevier; 2013. p. 188-98.

10. Nasipuri RN. Evaluation of cassava starch as tablet binder and disintegrants. J Med Pharm Marketing 1975;4:17.

11. Okhamafe OA, Igboechi A, Obaseki TO. Evaluation of a hospitalbased community liaison pharmacy service in Northern Ireland. Pharm World J 1991;8:120-30.

12. Shailender M. Compression physics of pharmaceutical powders. Int J Pharm Sci Res 2012;3:1580-92.

13. Pant, Sumedha, Malviya Rishabha, Sharma Pramod. Extraction and characterisation of Boswellia sarratia gum as a pharmaceutical excipient. Polim Med 2015;45:25-30.

14. Pavia DL, Lampman GM, Kriz GS. Introduction to spectroscopy: a guide to students of organic chemistry. $3^{\text {rd }}$ ed. Thomas Learning Inc. Washington, United States; 2001. p. 20-47.

15. Eckert M, Peciar P, Krok A, Fekete R. Application of compaction equations for powdered pharmaceutical materials. Sci Proc 2015;23:6-11.

16. Antonio Zenon, Antunes Teixeira. Compaction characteristics of the powder from the seed coat of Tingui (Magonia pubescens). Estud Biol 2007;29:277-82.

17. Kumar V, Kothari SA, Banker GS. Compression, compaction, and disintegration properties of low crystallinity celluloses produced using different agitation rates during their regeneration from phosphoric acid solutions. AAPS Pharm SciTech 2001;2:22-8.

18. Bamiro Oluyemisi Adebowale, Odebo Oluwatomi, Bakare Lateef Olugbenga. Compressional properties of metronidazole tablet formulations containing Aloe vera as a binding agent. Int J Pharm Pharm Sci 2014;6:261-4.

19. Edward Echevrri, Jhon Rojas, Mauricio Bedoya. A new enhanced sorbitol: calcium diphosphate composite as a direct compression excipient: a comparative study. Int J Pharm Pharm Sci 2016;8:43-9.

20. Odeku OA. The compaction of pharmaceutical powders; 2007. Available from: http://www.pharmainfo.net/reviews/ compaction-pharmaceuticalpowders. [Last accessed on $12 \mathrm{Sep}$ 2017].

21. Akpabio EI, Ekong US, Uwah TO, Ekpa ED, Ubolum PME, Jacobs GE, et al. Formulation and evaluation of sustained release tablets using Lesianthera africana gum. Nig J Pharm Appl Sci Res 2016;41-8. 